\title{
To Assess the Effectiveness of Nesting on Posture and Movements among Newborns in Selected Hospitals of Wardha District
}

\author{
Khushbu Manohar Meshram¹, Shalini Hemraj Lokhande², Prerna Tarachand Sakharwade ${ }^{3}$ \\ 1, 2, 3 Department of Child Health Nursing, SRMM College of Nursing, Datta Meghe Institute of Medical \\ Sciences (Deemed to Be University) Sawangi (Meghe) Wardha, Maharashtra, India.
}

\section{ABSTRACT}

\section{BACKGROUND}

Healthy posture can enhance sleep breathing and digestion, and protects internal organs from cramping. Strong posture may enhance quality of life. The fetus inutero has consistent, dynamic uterine boundaries that continually promote return to a flexed midline position following periods of activity. Conversely, infants in the neonatal intensive care unit are subjected to the effect of gravity and have a tendency to assume flattened postures especially when they are either preterm or sick. This places the infant at increased risk of developing a typical posture and movement patterns both in the short and long term. The study aims to determine the effectiveness of nesting on posture and movements among the new-borns in selected hospitals of Wardha.

\section{METHODS}

A quasi-experimental design was used to conduct this study. Purposive sampling technique was used for the new-borns in selected hospital of Wardha, among 60 new-borns (trial and control groups will include 30 new-borns each). A questionnaire was used to collect socio-demographic data of children and mothers, and a revised standardised checklist on the Infant Posture and Motor Appraisal scale was employed to compare the pose and movement of new-born babies. Following the pre-test, in the experimental population, care was provided to the new-born children, i.e., the baby may be placed in a prone position or on the side with flexed extremities by supplying a "nest" with a rolling blanket. The upper part of the child's body is slightly elevated, which represents a spot as it's "cradled in the arm." Intervening nesting was given in 2 periods for 3 days for 15 minutes. The post test was carried out on the 4th day of the modified observational checklist of the Infant Posture and Motor Assessment scale 'for the assessment of the posture and motor performance of new-born babies.

\section{RESULTS}

In control group $13.33 \%$ of new-borns had poor level of nesting on posture and movements, $66.67 \%$ had average, $13.33 \%$ had good and $6.67 \%$ of the new-borns had excellent level of nesting on posture and movements. Mean nesting on posture and movements score was $5.36 \pm 2.02$ and mean percentage score was $44.72 \pm$ 16.87. And in experimental group $13.33 \%$ of new-borns had poor level of nesting on posture and movements, $23.33 \%$ had average, $6.67 \%$ had good and $56.67 \%$ of the new-borns had excellent level of nesting on posture and movements. Mean nesting on posture and movements score was $8.13 \pm 4.02$ and mean percentage score was $67.77 \pm 33.52$.

\section{CONCLUSIONS}

Nesting is an indicator of relaxation that simulates a sense of lack of room in utero and making the infant less jittery. Nesting encourages the transition of the sleep cycle from intermittent disrupted periods into deep relaxed nights and happier days, thereby saving energy (may be wasted in crying) and reducing weight loss.

\section{KEY WORDS}

Roosting or Birdhouse, Position, Neonates.
Corresponding Author: Khushbu Manohar Meshram, Smt. Radhikabai Meghe Memorial College of Nursing, Sawangi (Meghe) Wardha, Maharashtra, India.

E-mail: khushbupande86@gmail.com

DOI: $10.14260 /$ jemds $/ 2022 / 8$

How to Cite This Article:

Meshram KM, Lokhande SH, Sakharwade PT. To assess the effectiveness of nesting on posture and movements among newborns in selected hospitals of wardha district. J Evolution Med Dent Sci 2022;11(01):39-43, DOI: $10.14260 /$ jemds $/ 2022 / 8$

Submission 28-08-2020,

Peer Review 22-10-2020,

Acceptance 28-10-2020,

Published 13-01-2022.

Copyright (C) 2022 Khushbu Manohar Meshram et al. This is an open access article distributed under Creative Commons Attribution License [Attribution 4.0 International (CC BY 4.0)] 


\section{BACKGROUND}

Newborns are having too many issues with adjustment soon after delivery. The temperature is maintained when they are in the womb of the mother and the flexed position also provides the baby with a lot of comfort. The striking difference between intrauterine setting and comprehensive neonatal care unit is obvious. Sensory effect was postulated to be adversely affecting the outcome in the preterm infant neurodevelopment. Developmental therapy, introduced in a strategy was intended to resolve environmental problems in the mid-1980s. Strategies used to adjust the extra uterine syndrome includes the monitoring of external stimulation, the clustering of care tasks and the pre-determined placement or sleep for the child providing stability and provision of longer rest times as in the intrauterine climate. ${ }^{1}$

The in utero fetus has strong, fluid uterine boundaries which are continuously promoting movements to return to a flexed midline position after periods of development conversely; infants are subject to the effect of gravity in the neonatal intensive care unit and tend to assume flattened postures especially when they are either preterm or sick. It puts the infant at greater risk of developing both short and long-term typical posture and activity patterns. A good placement of the support can help foster normal structural alignment. Proper placement can help the baby develop proper balance and improve muscle coordination. Every hospital really has a little nest that is a cotton strap towelling nest. The infant lies in the crib, and the cotton ties are drawn around the infant to make them feel safe and happy. ${ }^{2}$

L Rönnqvist, B Hopkins carried out this research work, preference for the head position was studied in 20 awake new-borns who differed in terms of sex and delivery. They were placed on a custom-built platform to reduce the effect on trunk posture and skull shape of gravity and asymmetries. By using the global scoring system, maintaining the head in midline was comparable in length with that recorded for babies at 2 - 3 months. This suggests that the neural mechanisms responsible for achieving and maintaining a mid-line position are present at birth, but are not expressed functionally due to a lack of adequate power in the antigravity muscles of the neck. ${ }^{3}$

\section{METHODS}

A quasi-experimental research design has been used in this study. The setting of the study was selected in the postnatal ward of selected hospitals in Wardha among 60 new-borns. 30 new-borns, each will be included in both the experimental and control group. The data collection instruments used was the following:

- Approval from authority.

- Select sample as per criteria.

- Collect data as per plan below.

Questionnaire was used on obtaining and modifying child, mother's socio-demographic data, observational checklist on the Infant Position and Motor Performance System for the assessment of the baby's attitude and activity. Following the pre-test, care was given to new-borns in the experimental population, i.e., by supplying the baby with flexed extremities, the baby may be placed in a prone position or at the side. The upper portion of the baby's body is slightly elevated, suggesting a spot when it is "cradled in the arm'. Intervention-nesting was given for $15 \mathrm{~min}$ in 2 periods for 3 days without interruption in control community. The post test was conducted on the 4th day, updated observational checklist of the Infant Posture and Motor Evaluation scale" for measuring new-born babies' posture and motor performance.

\section{Ethical Issues}

The study was conducted during December 2017 and the setting was selected at the Sawangi Meghe, Wardha, A.V.B.R Hospital, after getting ethical permission from the institutional ethics committee. Letter approval Ref no DMIMS (DU)/2016-17/3088 dated on 16/07/2016. Besides this, proper permission was taken from the chief medical officer of the hospital authorities. Informed consent was obtained from parents of the new-borns.

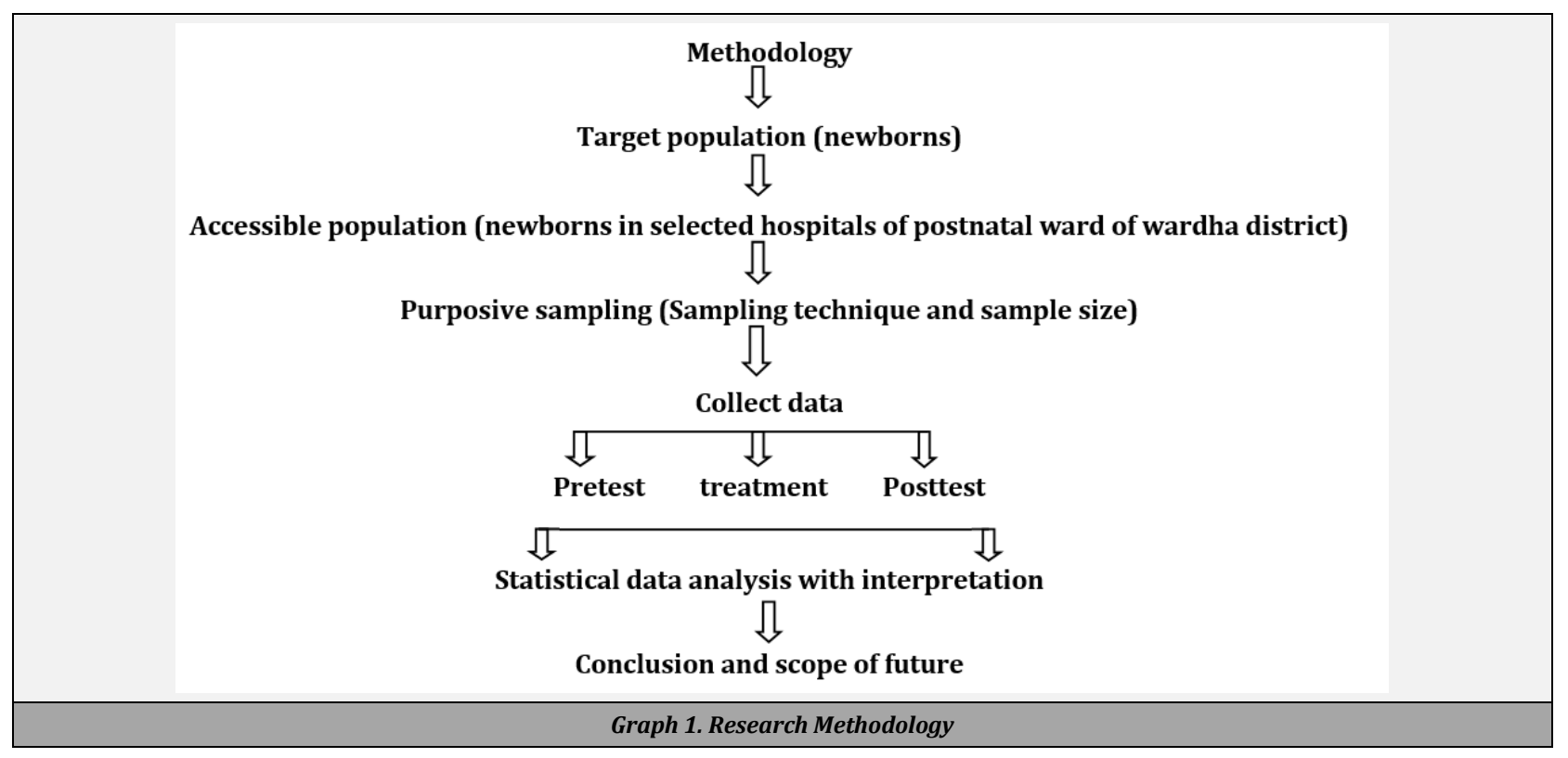




\section{Hypothesis}

H1: There will be a significant difference between experimental and control groups in mean post-test score of posture and movements of new-borns.

H2: A significant association will exist between the posture and movement of new-borns and their selected personal variables, such as age, sex, mode of delivery, baby weight.

\section{Inclusion Criteria}

- All new-borns $<36$ weeks of gestational age.

- New-borns admitted to the postnatal ward between $0-28$ days of age.

- Parents who are willing to give consent.

\section{Exclusion Criteria}

- Neonates who were having malformations or neurological defects

\section{Assumption}

Assumption of the study is nesting improves the posture and movements of new-borns.

\section{Statistical Analysis}

The demographic data was analysed in terms of frequency and percentage, gathered in pre-test stage. The cumulative $t-$ test was used to measure the pre-and post-test sensitivity levels. The chi-square approach was used after the analysis to determine the relationship between the selected predictor with the score of practice and the knowledge score. The data was analysed using version 20.00 of SPSS. A p value of 0.05 has been taken into consideration.

\section{RESULTS}

This segment deals with the ratio wise distribution of newborns in terms of demographic characteristics. 50 per cent of mothers of new-borns in the experimental group and 33.33 per cent in the control group were aged 26 - 30 years, 43.30 per cent in the experimental group and 53.3 per cent in the control group were aged 31 - 35 years and 6.70 per cent in the experimental group and 13.2 per cent in the control group were in the age group of 35 - 40 years. $66.70 \%$ percent mothers of new-borns in experimental group and $40 \%$ in control group were primipara and $33.3 \%$ in experimental group and $60 \%$ in control group were multiparas. 22.30 percent in the experimental group and 10 percent in the control group were in the 1 - 7-day age group, 63.3 percent in the experimental group and 40 percent in the control group were in the $8-14$ - day age group, 13.30 percent in the experimental group and 23.30 percent in the control group were in the 15 - 21 - day age group and 26.70 percent in the control group were new-borns. 33.30 percent of experimental group new-borns and 66.70 percent of control group new-borns were males and 66.70 percent of experimental group new-borns, and 33.30 percent were control group females. 26.70 percent of experimental-group new-borns and 66.70 percent of control-groups were delivered normally, and 73.30 percent of experimental-group new-borns and 33.30 percent of control-groups were delivered through Caesarean section. 43.30 percent of newborns in experimental group and 36.7 percent in control group were in $2-2.5 \mathrm{~kg}$ weight group. 33.3 percent of newborns in experimental group and 23.3 percent in control group were in $2.5-3 \mathrm{~kg}$ weight group. 23.3 percent of experimental group and 40 percent of control group were in 3 - $3.5 \mathrm{~kg}$ weight group.

\begin{tabular}{|c|c|c|}
\hline Demographic Variables & Experimental Group & Control Group \\
\hline \multicolumn{3}{|c|}{ Age (yrs.) of Mother } \\
\hline $20-25$ yrs. & $0(0 \%)$ & $0(0 \%)$ \\
\hline 26 - 30 yrs. & $15(50 \%)$ & $10(33.3 \%)$ \\
\hline $31-35$ yrs. & $13(43.3 \%)$ & $16(53.3 \%)$ \\
\hline 36 - 40 yrs. & $2(6.7 \%)$ & $4(13.2 \%)$ \\
\hline \multicolumn{3}{|c|}{ Parity } \\
\hline Primipara & $20(66.7 \%)$ & $12(40 \%)$ \\
\hline Multipara & $10(33.3 \%)$ & $18(60 \%)$ \\
\hline \multicolumn{3}{|c|}{ Age (yrs.) of Baby } \\
\hline 1 - 7 days & $7(23.3 \%)$ & $3(10 \%)$ \\
\hline 8 - 14 days & $19(63.3 \%)$ & $12(40 \%)$ \\
\hline 15 - 21 days & $4(13.3 \%)$ & $7(23.3 \%)$ \\
\hline 22 - 28 days & $0(0 \%)$ & $8(26.7 \%)$ \\
\hline \multicolumn{3}{|c|}{ Sex of the Baby } \\
\hline Male & $10(33.3 \%)$ & $16(66.7 \%)$ \\
\hline Female & $20(66.7 \%)$ & $14(33.3 \%)$ \\
\hline \multicolumn{3}{|c|}{ Type of Delivery } \\
\hline Normal & $8(26.7 \%)$ & $20(66.7 \%)$ \\
\hline Caesarean & $22(73.3 \%)$ & $10(33.3 \%)$ \\
\hline Vacuum & $0(0 \%)$ & $0(0 \%)$ \\
\hline Forceps & $0(0 \%)$ & $0(0 \%)$ \\
\hline \multicolumn{3}{|c|}{ Weight (kg) of the Baby } \\
\hline $1.5-2 \mathrm{~kg}$ & $0(0 \%)$ & $0(0 \%)$ \\
\hline $2-2.5 \mathrm{~kg}$ & $13(43.3 \%)$ & $11(36.7 \%)$ \\
\hline $2.5-3 \mathrm{~kg}$ & $10(33.3 \%)$ & $7(23.3 \%)$ \\
\hline $3-3.5 \mathrm{~kg}$ & $7(23.3 \%)$ & $12(40 \%)$ \\
\hline \multicolumn{3}{|c|}{$\begin{array}{c}\text { Table 1. Percentage Wise Distribution of New-Borns According to } \\
\text { Their Demographic Characteristics. }\end{array}$} \\
\hline & & \\
\hline
\end{tabular}

Table 2: Assessment of level of nesting position on posture and movements in control group shows that $13.33 \%$ of new-borns had poor level of nesting on posture and movements, $66.67 \%$ had average, $13.33 \%$ had good and 6.67 $\%$ of the new-borns had excellent level of nesting on posture and movements. Mean nesting on posture and movements score was $5.36 \pm 2.02$ and mean percentage score was 44.72 \pm 16.87 .

\begin{tabular}{|cccc|}
\hline $\begin{array}{c}\text { Level of Nesting } \\
\text { Position on Posture } \\
\text { and Movements }\end{array}$ & $\begin{array}{c}\text { Score } \\
\text { Range }\end{array}$ & $\begin{array}{c}\text { Level of Nesting Position on Posture } \\
\text { and Movements } \\
\text { No of New-Borns }\end{array}$ & $\begin{array}{c}\text { Percentage } \\
\text { Poor }\end{array}$ \\
$\begin{array}{c}\text { Average } \\
\text { Good }\end{array}$ & $26-50 \%$ & 4 & 13.33 \\
Excellent & $51-75 \%$ & 7 & 23.33 \\
Minimum score & $76-100 \%$ & 17 & 6.67 \\
Maximum score & 0 \\
Mean score & 12 \\
Mean \% Score & $8.13 \pm 4.02$ \\
Table 2. Assessment with Level of Nesting Position on \\
Posture and Movements in the Experimental Group \\
\hline
\end{tabular}

Table 3: Assessment with level of nesting on posture and movements in experimental group shows that $13.33 \%$ of 
new-borns had poor level of nesting on posture and movements, $23.33 \%$ had average, $6.67 \%$ had good and 56.67 $\%$ of the new-borns had excellent level of nesting on posture and movements. Mean nesting on posture and movements score was $8.13 \pm 4.02$ and mean percentage score was 67.77 \pm 33.52 .

\begin{tabular}{|c|c|c|c|}
\hline \multirow{2}{*}{$\begin{array}{l}\text { Level of Nesting } \\
\text { Position on Posture } \\
\text { and Movements }\end{array}$} & \multirow{2}{*}{$\begin{array}{l}\text { Score } \\
\text { Range }\end{array}$} & \multicolumn{2}{|c|}{$\begin{array}{l}\text { Level of Nesting Position on } \\
\text { Posture and Movements }\end{array}$} \\
\hline & & No of Newborns & Percentage \\
\hline Poor & $0-25 \%$ & 4 & 13.33 \\
\hline Average & $26-50 \%$ & 20 & 66.67 \\
\hline Good & $51-75 \%$ & 4 & 13.33 \\
\hline Excellent & $76-100 \%$ & 2 & 6.67 \\
\hline \multicolumn{2}{|l|}{ Minimum score } & \multicolumn{2}{|l|}{2} \\
\hline \multicolumn{2}{|l|}{ Maximum score } & \multicolumn{2}{|l|}{11} \\
\hline \multicolumn{2}{|l|}{ Mean score } & \multicolumn{2}{|c|}{$5.36 \pm 2.02$} \\
\hline \multicolumn{2}{|l|}{ Mean \% Score } & \multicolumn{2}{|c|}{$44.72 \pm 16.87$} \\
\hline \multicolumn{4}{|c|}{$\begin{array}{l}\text { Table 3. Assessment with Level of Posture and Movements } \\
\text { in the Control Group }\end{array}$} \\
\hline & & & \\
\hline
\end{tabular}

Table 4: It provides a comparison of the performance of new-borns nesting on posture and gestures. Meanwhile, standard deviation and mean differential values are measured and the unpaired ' $t$ ' measure of the newborns is applied at significant level of 5 per cent. The tabulated value for $\mathrm{n}=60-2$ was 2.00 , i.e., 58 degrees of independence. The estimated ' $t$ ' value, i.e., 3.36, is far better than the tabulated value at a 5 percent level of meaning for average pose and motion nesting, which is statistically appropriate. Hence, it is statistically interpreted that the nesting on posture and movements among new-borns was effective. Thus, the $\mathrm{H}_{1}$ is accepted.

\begin{tabular}{|cccccc|}
\hline Group & Mean & SD & $\begin{array}{c}\text { Mean } \\
\text { Difference }\end{array}$ & t-Value & P-Value \\
Experimental & 8.13 & 4.02 & $2.76 \pm 0.82$ & 3.36 & 0.001 \\
Control & 5.36 & 2.02 & & $\mathrm{~S}, \mathrm{p}<0.05$ \\
\hline $\begin{array}{l}\text { Table 4. Significance of Difference between Nesting Position on } \\
\text { Posture and Movements in the Experimental and Control Groups }\end{array}$ \\
\hline $\mathrm{N}=60$
\end{tabular}

The comparison of nesting position on posture and movements among newborns was statistically significant with their nesting on posture and movements.

\section{DISCUSSION}

A study to evaluate lying in a nest affects the posture and spontaneous movement of healthy preterm infants was carried out in the year 2007 Feb 22. For this study, the researcher took 10 healthy preterm three age group infants, i.e. 30 to 33 weeks, 34 to 36 weeks and 37 to 40 weeks. Infants went through repeated video monitoring in the supine posture inside and outside the nest. The pose was checked before and after general activity by recognising the dominant posture trend and the study findings show that the nest promotes flexed alignment of the limbs with adduction of the elbows, enables graceful gestures of the wrist towards and across the midline, and decreases sudden movements and frozen position of the arms and legs. ${ }^{4}$ The following research, was carried out on childcare strategies that could help preterm infants cope better with the NICU climate. An adverse event will adversely affect children's development, especially the brain. Info was taken out by the 2 authors. Meta-analysis was carried out with each intervention. ${ }^{5}$

Study on premature babies and painful operations was performed in the year 2000 in June. Managing the pain of premature babies is a difficult challenge for breastfeeding. Particularly this group of babies are physiologically frail. Painful procedures are harmful to physiological stability and self regulating ability, which includes maintaining motor control and stable sleep / wake cycles. It's difficult to measure discomfort in premature babies. Big stress markers provide grimaces to the face and medical measures such as pulse rate and oxygen saturation are also affected. The assessment of premature infant pain is one method explicitly developed for preterm babies. Nonpharmacological steps such as swaddling or sleeping and giving a pacifier are effective methods for helping children deal with pain procedures. $^{6}$ A community of scientists performed a needbased assessment of the paediatricians, psychotherapists, and biologists on the impact of newborn nesting. Only half of the parents who still put infants on their foreheads to sleep have come to know about this as a very important risk factor for sudden infant death syndrome (SIDS). Second justification for nesting research was motivated by parental interaction. The third theory was that they evaluated the evidence-based methods and scientific studies were performed to find out the effectiveness of nesting position on newborns. ${ }^{7}$

Another study supported done by Jagadeeswari J Swathi D aims to determine the efficacy of posture comfort nesting in babies with a low birth weight. A comprehensive quasiexperimental research design was carried out among 30 babies with a low birth weight. Convenient sampling technique was used to select samples. A semi-structured interview was used to gather demographic data, and a comfort scale was used to assess posture. In the experimental community, the babies were placed inside the nest in a side-lying position, who were then rolled in a blanket. After an hour, the ease of stance was re-evaluated. The findings of the study indicate substantial increase in posture satisfaction in the experimental community as opposed to the control group after the $\mathrm{p}<0.001$ standard intervention. This reveals that nesting is of great importance in the experimental group as it improves the posture comfort of the new-born, which in turn promotes growth and development of babies with low birth weight. This suggests that nesting is an efficient and healthy approach for enhancing posture ease, preserving vital signs and helping to grow babies with low birth weight and supporting sound sleep in babies with low birth weight. ${ }^{8}$

Head-place choice was observed in 20 new-borns who were awake whose age and sex were different. They were fixed on a custom frame to minimise the influence of gravity and asymmetry on the position of the trunk and the stability of the skull. Maintaining the head at midline was comparable in length to that recorded by the global score system for babies at 2 to 3 months. This means that the neural mechanisms responsible for achieving and maintaining a midline position are present at puberty, but are not clinically expressed due to a lack of sufficient strength in the antigravity muscles of the neck. ${ }^{9}$ 
Another research sponsored was a longitudinal study to assess the impact of body support on physiological and functional posture from two separate lying positions in 30 qualifying preterm neonates, granted between 28 and 35 weeks of gestation. The premature neonates demonstrated improvements in postural growth, the findings of the study suggested the benefits of placement with specially tailored assistance such as "cocoons" facilitating optimum prophylactic neurobehavioral and posture treatment for premature neonates. ${ }^{10}$

\section{CONCLUSIONS}

"Nesting" is an indication of calmness that simulates a feeling of lack of space in the uterus, leaving the baby less jittery or vulnerable to shock. Nesting encourages the reversal of the sleep cycle from intermittent disrupted periods to deep calm nights and happier days, thereby saving time and minimising weight loss. The flexed location reduces the region exposed to the surface. Numerous studies and also present research scholars suggest that nesting is a safe and beneficial practice in promoting the comfort and proper positioning after birth of the new-born babies.

Data sharing statement provided by the authors is available with the full text of this article at jemds.com.

Financial or other competing interests: None.

Disclosure forms provided by the authors are available with the full text of this article at jemds.com.

\section{REFERENCES}

[1] Oyen N, Markestaad T. Facilitation of developmental care for high risk neonates: an intervention study. (Nursing Science) PhD thesis 2011.

[2] Darmwneward. Positioning of preterm and sick neonate. Early Human Development 2003;48(1-2):35-46.

[3] Rönnqvist L, Hopkins B. Head position preference in the human newborn: a new look. Child Dev 1998;69(1):1323.

[4] Ferrari F, Bertoncelli N, Gallo C, et al. Posture and movement in healthy preterm infants in supine position in and outside the nest. Arch Dis Child Fetal and Neonatal Ed 2007;92(5):48-52.

[5] Nair M, Gupta G, Jatana SK. NICU environment: can we be ignorant? Med J Armed Forces India 2003;59(2):93-5.

[6] Hemingway M, Oliver S. A new way to understand your baby's crying. Neonatal Intensive Care 2002;13(6):1822.

[7] Mitchell A, Roane DB. The premature infant and painful procedures. Advanced Neonatal Care 2003;3(5):241-9.

[8] Jagadeeswari J, Swati D. Effectiveness of nesting on posture comfort among low birth weight babies in neonatal intensive care unit. International Journal of Research in Pharmaceutical Sciences 2020;11(3):3396401.

[9] Hunter J, Kenner C, McGrath JM. Developmental care of newborn and infant: a guide for health professionals. $3^{\text {rd }}$ edn. New Delhi: St. Louis Elsevier Publishers (P) Ltd 2004:219-319.

[10] Vaivre-Douret L, Golse B. Comparative effects of two positional support on neurobehavioral and postural development in preterm neonates. J Perinat Neonatal Nurs 2007;21(4):323-30. 